\title{
Study of Mesomorphism in Isomeric and Nonisomeric Linear and Nonlinear Chalconyl Series
}

\author{
Vinay.S.Sharma ${ }^{1}$, R. B. Patel ${ }^{*}$ \\ Chemistry Department, K.K.Shah Jarodwala Maninagar Science College, Gujarat University, \\ Ahmedabad 380008, Gujarat, India. \\ Email address: vinaysharma3836@gmail.com, \\ *roshanpatel770@gmail.com
}

Keywords: Mesomorphs, Liquid crystal, Smectic, Nematic, Enantiotropy.

\begin{abstract}
A novel nonlinear chalconyl homologous series of ester: $\mathrm{RO}-\mathrm{C}_{6} \mathrm{H}_{4}-\mathrm{COO}-\mathrm{C}_{6} \mathrm{H}_{4}(\mathrm{~m})-$ $\mathrm{CO}-\mathrm{CH}: \mathrm{CH}-\mathrm{C}_{6} \mathrm{H}_{4}-\mathrm{OC}_{16} \mathrm{H}_{33}(\mathrm{n})$ (para) have been synthesized and studied with a view to understand and establish the relation between thermotropic liquid Crystal (LC) properties and geometrically nonlinear shaped molecular structure. Homologous series consists of thirteen members $\left(\mathrm{C}_{1}\right.$ to $\left.\mathrm{C}_{18}\right)$ whose enantiotropic nematogenic mesomorphism commences from $\mathrm{C}_{6}$ homologue without exhibition of smectic property. $\mathrm{C}_{1}$ to $\mathrm{C}_{5}$ homologues are nonmesomorphic. Transition temperatures and textures of homologues were determined by an optical polarising microscopy equipped with a heating stage (POM). Transition curves of a phase diagrams (Cr-N/I and N-I) behaved in normal manner. N-I transition curve exhibited odd-even effect. Textures of a nematic phase are threaded or schlieren. Analytical and spectral data supported molecular structures of homologues. Thermal stability for nematic is $104.5^{\circ} \mathrm{C}$ whose degree of mesomorphism vary minimum of $13.0^{\circ} \mathrm{C}$ to maximum of $37.0^{\circ} \mathrm{C}$. Group efficiency order for nematic is derived by comparing present novel series with structurally analogous other homologous series. Thus, homologous series of present investigation is nematogenic with absence of smectic property and of middle ordered melting type with considerable degree of mesomorphism.
\end{abstract}

\section{INTRODUCTION}

Study of chalconyl ester derivatives as liquid crystals (LC) [1] either of thermotropic or lyotropic type is an important from point of view of their applicability and usefulness in the benefit of mankind $[2,3,4,5,6,7,8,9]$. Present investigation is planned with a view to understand and establish the effect of molecular structure on LC properties of isomeric and nonisomeric, linear and nonlinear shaped homologous series of thermotropic chalconyl ester derivatives $[10,11,12,13,14]$. The novel chalconyl esters of nonlinear shaped will be synthesized and characterized by an optical polarising microscopy (POM) equipped with a heating stage, analytical data and spectral data from synthesis of a homologous series, which will consist of three phenyl rings, two central bridges and two terminals $-\mathrm{OR}$ and $-\mathrm{OC}_{16} \mathrm{H}_{33}$. Number of homologous series with one ester central group and other central bridge $-\mathrm{CH}=\mathrm{N}-,-\mathrm{N}=\mathrm{N}-,-\mathrm{CO}-\mathrm{CH}=\mathrm{CH}-,-\mathrm{CH}=\mathrm{CH}-\mathrm{CO}-,-\mathrm{COO}-\mathrm{CH}_{2}-,-\mathrm{CH}=\mathrm{CH}-\mathrm{COO}-\mathrm{CH}_{2}$ etc. are reported till the date $[15,16,17,18,19,20,21,22,23,24,25,26]$. Some thermometric data of novel homologues will be discussed and interpreted in terms of molecular rigidity and flexibility $[27,28,29,30]$ and then, LC properties and behaviours will be compared with structurally analogous or similar other series. The group efficiency order will be derived from thermal stability, degree of mesomorphism and the commencement of mesophase.

\section{EXPERIMENTAL}

\subsection{Synthesis:}

4-n- alkoxy Benzoic acids (A) prepared by modified method of Dave and Vora [31]. $\alpha-3$ hydroxyl benzoyl $\beta-4$-Hexadecyloxy phenyl ethylene (B) was prepared by usual established method [32]. Esters were synthesized by a literature method [33]. Thus, the Chalconyl - ester 
homologue derivatives were filtered, washed with sodium bicarbonate solution, dried and purified till constant transition temperatures, Alkyl halides, 3-hydroxy acetophenone, dicyclohexyl carbodimide, Dimethyl amino pyridine, DCM, MeOH, Acetone required for synthesis were used as received except solvents which were dried and distilled prior to use. The synthetic route to a series is mentioned in Scheme-1.

\section{Reaction Scheme}

Step-1<smiles>[R]Oc1ccc(C(=O)O)cc1</smiles>

Step-2

(A)<smiles>O=Cc1ccc(O)cc1</smiles>

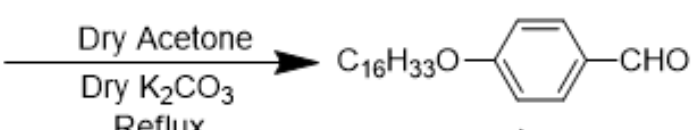
Reflux
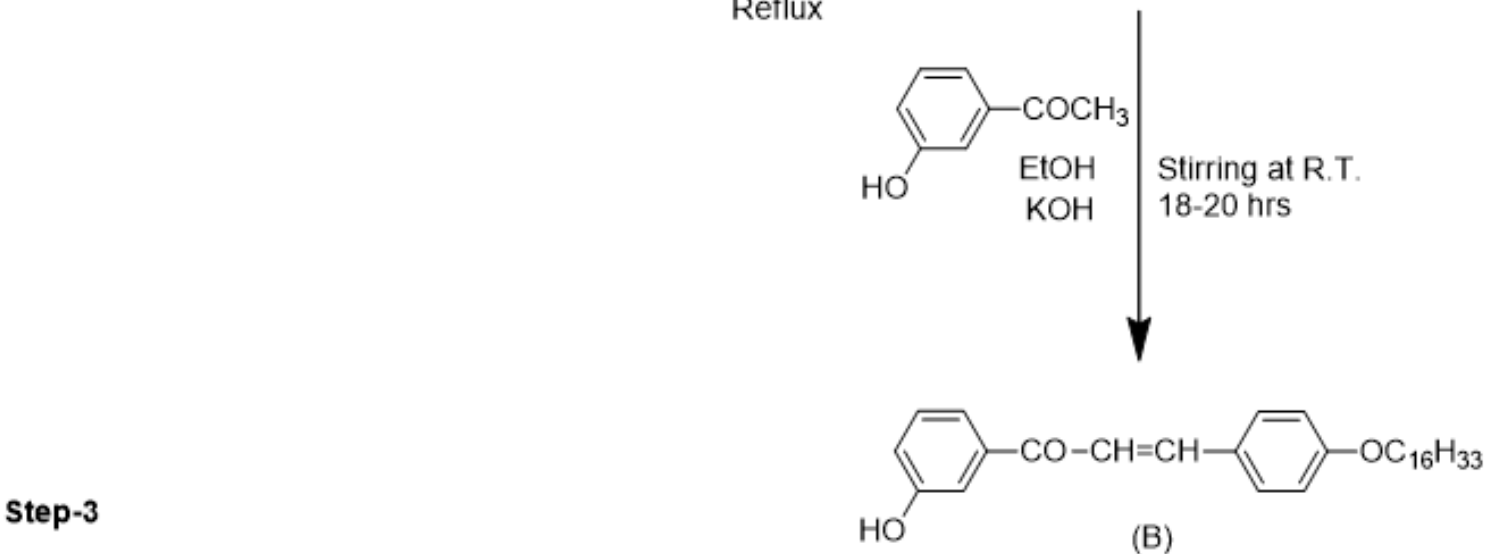<smiles>[R]Oc1ccc(C(=O)O)cc1</smiles>

(A)<smiles>CCCCCCCCCCCOc1ccc(C=COC(=O)c2cccc(C)c2)cc1</smiles>

(B)

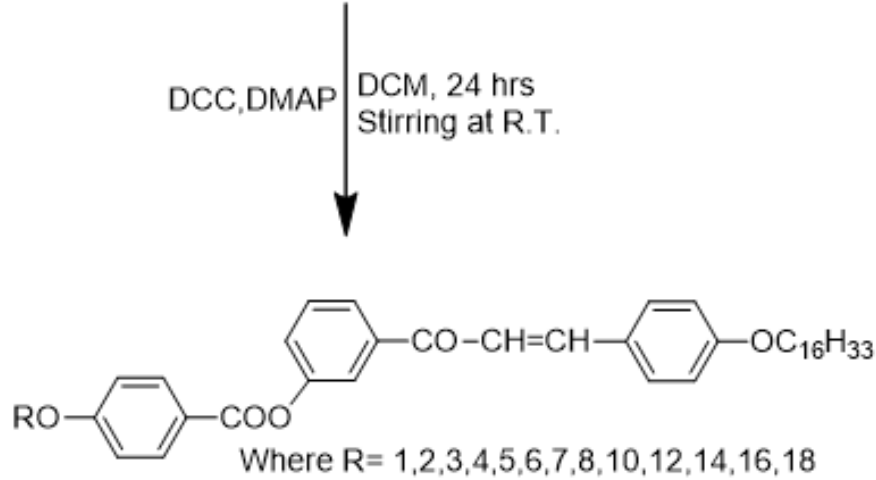

Scheme 1: Synthetic route to the Series-1.

\subsection{Characterization:}

Representative homologues of a series were characterised by elemental analysis, Infrared spectroscopy, ${ }^{1} \mathrm{H}$ NMR spectra. IR spectra were recorded by Perkin-Elmer spectrum GX, ${ }^{1} \mathrm{HNMR}$ spectra were recorded on Bruker using $\mathrm{CDCl}_{3}$ as solvent. Microanalysis was performed on PerkinElmer PE $2400 \mathrm{CHN}$ analyser (Table-1). Transition temperature and LC properties (Textures) were determined using an optical polarising microscopy equipped with heating stage. Texture of some homologues for nematic phase were determined by miscibility method (Figure-1). Thermodynamic quantities enthalpy $(\Delta \mathrm{H})$ and entropy $(\Delta \mathrm{S}=\Delta \mathrm{H} / \mathrm{T})$ are qualitatively discussed. 


\section{Analytical Data:}

Table 1: Elemental Analysis for (1) Propyloxy (2) Heptoloxy (3) Dodecyloxy and (4) Tetradecyloxy derivatives

\begin{tabular}{|c|c|c|c|c|c|}
\hline \multirow{2}{*}{ Sr. No. } & \multirow{2}{*}{ Molecular formula } & \multicolumn{2}{|c|}{ Elements \% found } & \multicolumn{2}{c|}{ Elements \% Calculated } \\
\cline { 3 - 6 } & & C & H & C & H \\
\hline 1 & $\mathrm{C}_{41} \mathrm{H}_{54} \mathrm{O}_{5}$ & 78.52 & 8.60 & 78.59 & 8.62 \\
\hline 2 & $\mathrm{C}_{45} \mathrm{H}_{62} \mathrm{O}_{5}$ & 79.13 & 9.06 & 79.17 & 9.09 \\
\hline 3 & $\mathrm{C}_{50} \mathrm{H}_{72} \mathrm{O}_{5}$ & 79.75 & 9.55 & 79.78 & 9.57 \\
\hline 4 & $\mathrm{C}_{52} \mathrm{H}_{76} \mathrm{O}_{5}$ & 79.94 & 9.72 & 80.00 & 9.74 \\
\hline
\end{tabular}

IR Spectra in $\mathrm{cm}^{-1}$ for Hexaloxy \& Decyloxy Derivatives:

Hexaloxy : 682 Polymethylene $\left(-\mathrm{CH}_{2}-\right)$ of $-\mathrm{OC}_{6} \mathrm{H}_{13}, 999\left(-\mathrm{C}-\mathrm{H}-\right.$ def. hydrocarbon in $\left.-\mathrm{OC}_{16} \mathrm{H}_{33}\right)$, 1114(-C-O-) Str, 1165, 1249 and 1379 ( $-\mathrm{C}-\mathrm{O}$ str in $-\left(\mathrm{CH}_{2}\right)$ n chain), 1462 (-C-H- def. in $\left.\mathrm{CH}_{2}\right)$, 1604, 1660 (-C=O group) and (-COO- ester group), 2848 and 2918 (-C-H str in $\left.\mathrm{CH}_{3}\right)$.

Decyloxy : 721 Polymethylene $\left(-\mathrm{CH}_{2}-\right) \mathrm{n}$ of $-\mathrm{OC}_{10} \mathrm{H}_{21}, 829(-\mathrm{C}-\mathrm{H}$ - def. m di-substituted-meta), 999 (-C-H- def. hydrocarbon of $\left.-\mathrm{OC}_{16} \mathrm{H}_{33}\right), 1168$ and 1257 ( $-\mathrm{C}-\mathrm{O}$ str in $-\left(\mathrm{CH}_{2}\right)$ n chain, 1467(-C-Hdef. in $\left.\mathrm{CH}_{2}\right), 1510$ ( $\left.-\mathrm{C}=\mathrm{C}-\right)$ str, 1607 and 1722 ( $-\mathrm{C}=\mathrm{O}$ group) and (-COO- ester group), 2848 and $2972\left(-\mathrm{C}-\mathrm{H}\right.$ str in $\left.\mathrm{CH}_{3}\right)$.

${ }^{1} \mathrm{HNMR}$ spectra in $\mathrm{CDCl}_{3}$ in $\boldsymbol{\delta} \mathbf{p p m}$ for Octyloxy \& Decyloxy Derivative:

Octyloxy : $0.87\left(\mathrm{t},-\mathrm{CH}_{3}\right.$ of $\left.-\mathrm{C}_{8} \mathrm{H}_{17}\right), 1.2-1.6\left(\mathrm{~m}, \mathrm{n}\right.$-poly methylene groups of- $\left.\mathrm{OC}_{8} \mathrm{H}_{17}\right), 1.8(\mathrm{~m}, \mathrm{n}$-poly methylene groups of $\left.-\mathrm{OC}_{16} \mathrm{H}_{33}\right), 3.5-3.8\left(\mathrm{~s},-\mathrm{OCH}_{2}-\mathrm{CH}_{2}\right.$ - of $\left.-\mathrm{OC}_{16} \mathrm{H}_{29}\right), 4.01\left(\mathrm{~s},-\mathrm{OCH}_{2}-\mathrm{CH}_{2}\right.$-of $\left.\mathrm{OC}_{8} \mathrm{H}_{17}\right), 6.51(\mathrm{~d},-\mathrm{CH}=\mathrm{CH}-), 6.9-7.4(\mathrm{~s},-\mathrm{CO}-\mathrm{CH}=\mathrm{CH}), 8.09$ (s,-disubstituted phenyl ring).

Decyloxy : $0.87\left(\mathrm{t},-\mathrm{CH}_{3}\right.$ of $\left.-\mathrm{C}_{10} \mathrm{H}_{21}\right), 1.5-1.6\left(\mathrm{~m}, \mathrm{n}\right.$-poly methylene groups of- $\left.\mathrm{OC}_{10} \mathrm{H}_{21}\right), 1.81(\mathrm{~m}, \mathrm{n}-$ poly methylene groups of $\left.-\mathrm{OC}_{16} \mathrm{H}_{33}\right), 3.3-3.8\left(\mathrm{~s},-\mathrm{OCH}_{2}-\mathrm{CH}_{2}\right.$-of $\left.-\mathrm{OC}_{16} \mathrm{H}_{33}\right), 4.0$ (s, $-\mathrm{OCH}_{2}-\mathrm{CH}_{2}$-of $\left.\mathrm{OC}_{10} \mathrm{H}_{21}\right), 6.8(\mathrm{~d},-\mathrm{CH}=\mathrm{CH}-)$ 6.9-7.4(s,-CO-CH=CH), 8.1(s,-disubstituted phenyl ring).

Table 2: Textures of Nematic phase by miscibility method for $\mathrm{C}_{5}, \mathrm{C}_{8}, \mathrm{C}_{14}, \mathrm{C}_{16}$.

\begin{tabular}{|c|c|c|}
\hline Sr. No. & Homologue & Texture \\
\hline 1 & $\mathrm{C}_{5}$ & Schlieren \\
\hline 2 & $\mathrm{C}_{8}$ & Threaded \\
\hline 3 & $\mathrm{C}_{14}$ & Droplets of nematic \\
\hline 4 & $\mathrm{C}_{16}$ & Schlieren \\
\hline
\end{tabular}

Texture by POM image

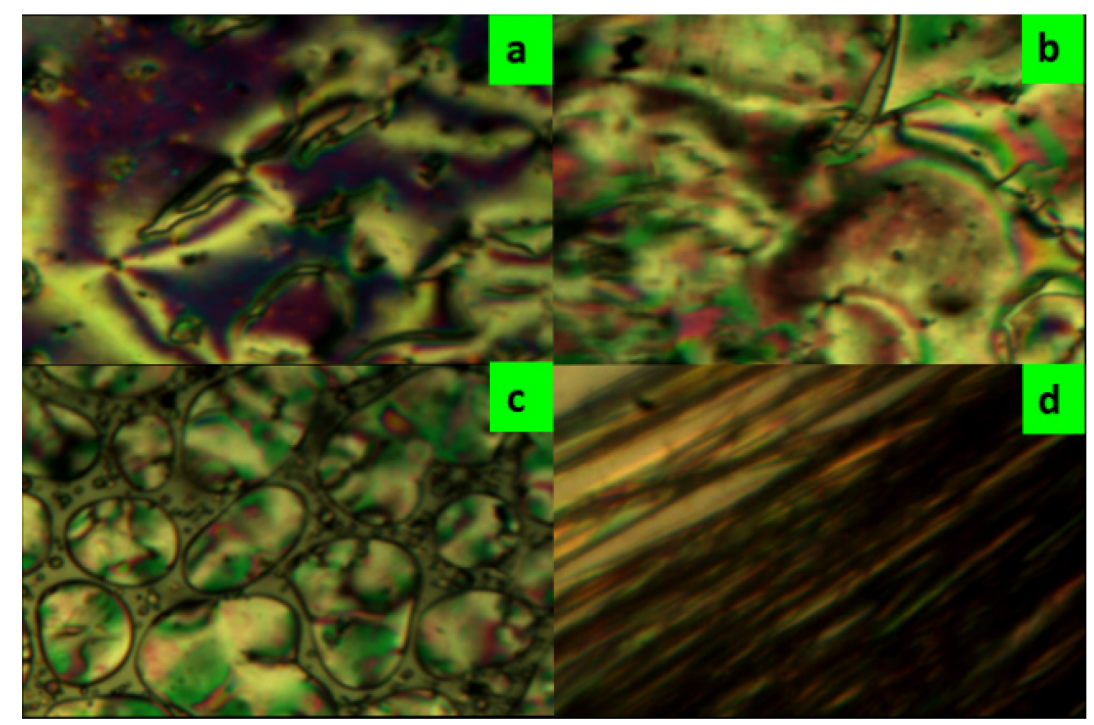


Figure 1: (A) Nematic phase of $\mathrm{C}_{6}$ at $81^{\circ} \mathrm{C}$. (B) Nematic phase of $\mathrm{C}_{7}$ at $75^{\circ} \mathrm{C}$. (C) Nematic phase of $\mathrm{C}_{14}$ at $83^{\circ} \mathrm{C}$. (D) Nematic phase of $\mathrm{C}_{12}$ at $80^{\circ} \mathrm{C}$.

Table 3: Transition Temperatures in ${ }^{\circ} \mathrm{C}$ for Series-1.

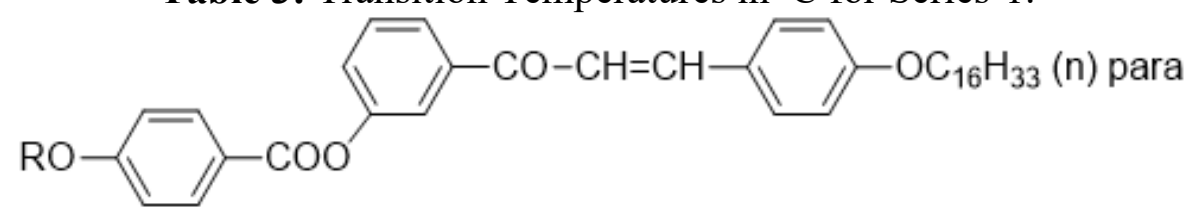

Homologous Series: $\alpha-3$-[4'-n-alkoxy benzoyloxy] phenyl- $\beta-4$ "-hexadecyloxy phenyl ethylenes

\begin{tabular}{|c|c|c|c|c|}
\hline \multirow[t]{2}{*}{ Sr.no } & \multirow[t]{2}{*}{$\mathrm{R}=\mathrm{n}$-alkyl group } & \multicolumn{3}{|c|}{ Transition temperatures in ${ }^{0} \mathrm{C}$} \\
\hline & & Smectic & Nematic & Isotropic \\
\hline 1 & $\mathrm{C}_{1}$ & - & - & 134.0 \\
\hline 2 & $\mathrm{C}_{2}$ & - & - & 139.0 \\
\hline 3 & $\mathrm{C}_{3}$ & - & - & 142.0 \\
\hline 4 & $\mathrm{C}_{4}$ & - & - & 129.0 \\
\hline 5 & $\mathrm{C}_{5}$ & - & - & 132.0 \\
\hline 6 & $\mathrm{C}_{6}$ & - & 81.0 & 118.0 \\
\hline 7 & $\mathrm{C}_{7}$ & - & 75.0 & 107.0 \\
\hline 8 & $\mathrm{C}_{8}$ & - & 82.0 & 110.0 \\
\hline 9 & $\mathrm{C}_{10}$ & - & 88.0 & 101.0 \\
\hline 10 & $\mathrm{C}_{12}$ & - & 80.0 & 106.0 \\
\hline 11 & $\mathrm{C}_{14}$ & - & 83.0 & 107.0 \\
\hline 12 & $\mathrm{C}_{16}$ & - & 72.0 & 96.0 \\
\hline 13 & $\mathrm{C}_{18}$ & - & 67.0 & 91.0 \\
\hline
\end{tabular}

\section{RESULT AND DISCUSSION}

$\alpha$-3-Hydroxy benzoyl- $\beta$-4'-hexadecyloxy phenyl ethylene (m.p. $78^{\circ} \mathrm{C}$, yield, $69.81 \%$ ) on condensation with dimeric 4-n-alkoxy benzoic acid yielded chalconyl esters $\left(\mathrm{C}_{1}\right.$ to $\left.\mathrm{C}_{18}\right)$, of which $\mathrm{C}_{6}$ to $\mathrm{C}_{18}$ homologues are enantiotropically nematogenic with absence of smectogenic character. Rest of the homologues ( $\mathrm{C}_{1}$ to $\mathrm{C}_{5}$ ) are nonliquid crystals. The transition temperatures of novel homologues (table-2) as determined by an optical polarizing microscopy (POM) equipped with a heating stage are lower than the corresponding dimeric aromatic n-alkoxy acids. A phase diagram (Figure-2) of a novel series consisted of Cr-N/I and N-I transition curves showing phase behaviours of series are obtained by linking like or related points of the graph plotted for numbers of carbon atoms present in n-alkyl chain $\mathrm{R}$ of left n-alkoxy group -OR versus transition temperatures of homologues. The Cr-N/I transition curve adopts a zigzag path of rising and falling with overall descending tendency and behaved in normal manner. The N-I transition curve initially rises and falls for odd and even members till $\mathrm{C}_{10}$ homologue, where curves for odd and even members are 
merging into each other and then N-I transition curve propagated as a single transition curve from and beyond $\mathrm{C}_{10}$ homologue of longer $\mathrm{n}$-alkyl chain $\mathrm{R}$ of left $-\mathrm{OR}$ flexible group and behaved in normal manner. The N-I curves for odd and even member are extrapolated to $\mathrm{C}_{5}$ and $\mathrm{C}_{4}$ homologues to highlight odd-even effect and to predict their probable latent transition temperatures (L.T.T.) $107.0^{\circ} \mathrm{C}$ and $123.0^{\circ} \mathrm{C}$ respectively; for nematic phase formation. The textures of nematic phase are threaded or schlieren. Analytical and spectral data confirms the structures of homologues. Thermal stability for nematic is 104.5 in average, whose, degree of mesomorphism is $13.0^{\circ} \mathrm{C}$ to $37^{\circ} \mathrm{C}$, Thus, novel series under discussion is nematogenic and of middle ordered melting type.

\section{Homologues series}

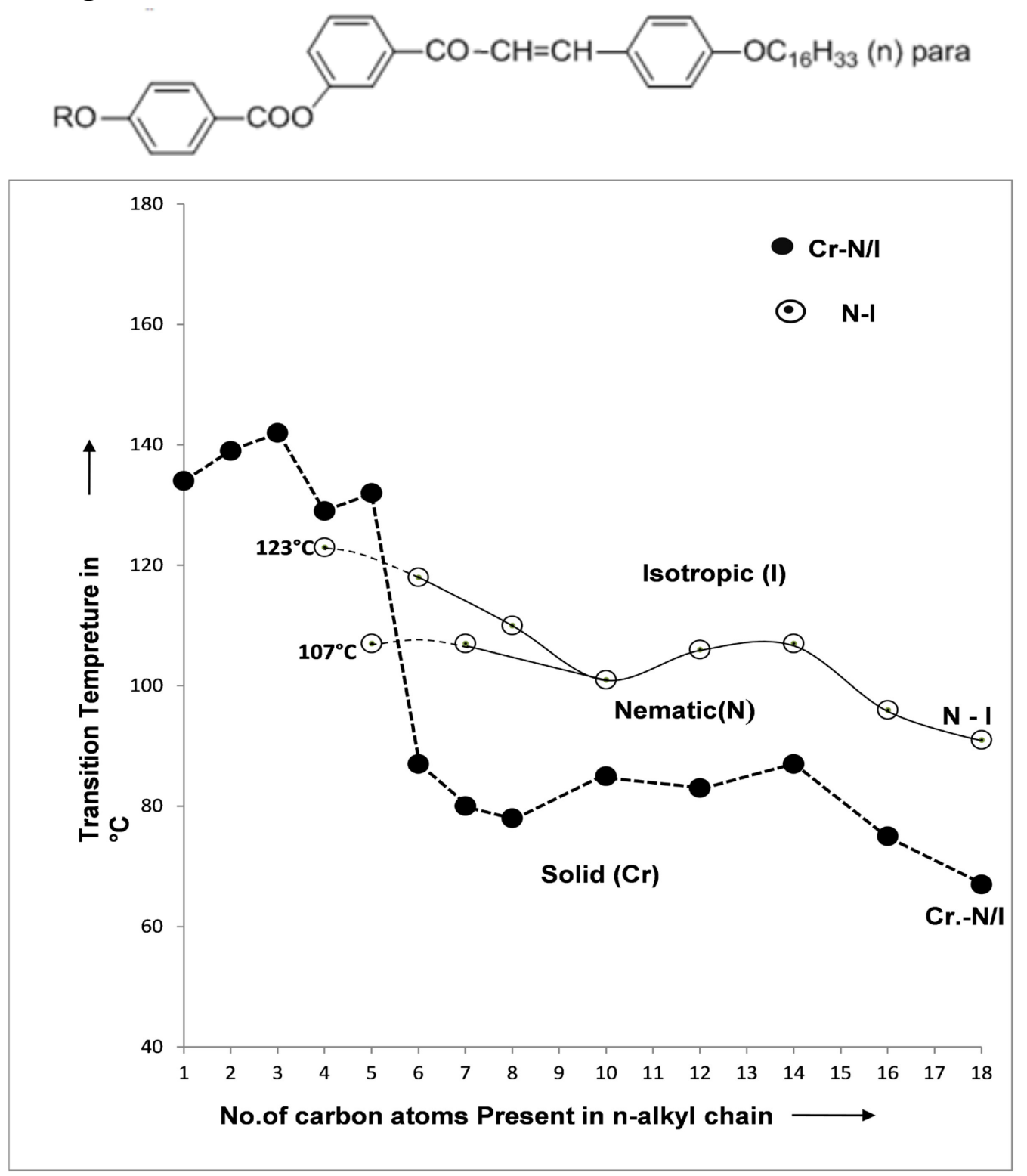

Figure 2: Phase behaviours of Series

The lowering of transition temperatures and the disappearance of dimerization of corresponding n-alkoxy aromatic acids are attributed to the process of esterification by breaking of hydrogen bonding between two molecules of n-alkoxy benzoic acids. The nonmesomorphicity of $\mathrm{C}_{1}$ to $\mathrm{C}_{5}$ homologues is attributed to their high crystallising tendency which arises due to low magnitudes of dispersion forces and low dipole-dipole interaction which results into unsuitable magnitudes of anisotropic forces of intermolecular end to end or lateral attractions as a consequence of unfavourable combined effects of molecular rigidity and /or flexibility. Therefore, the molecules 
of nonmesomorphs sharply transform into isotropic liquid from crystalline solid to isotropic liquid with bypassing of liquid crystalline state formation. However, the disaligned molecules of $\mathrm{C}_{6}$ to $\mathrm{C}_{18}$ homologues at an angle less than ninety degree with surface of floating; resists the exposed thermal vibrations to arranges themselves in stastically parallel orientational order for definite temperature range under floating condition. Thus, nematic mesophase formation persisted for $\mathrm{C}_{6}$ to $\mathrm{C}_{18}$ homologue under microscopic examination of a sample. The absence of lamellar packing of molecules in their crystal lattices causes absence of smectogenic property throughout the entire series. The molecules are randomly oriented in all possible directions from and beyond isotropic temperature, with high order of disorder or high entropy $(\Delta \mathrm{S}=\Delta \mathrm{H} / \mathrm{T})$; but, on cooling the same from and below isotropic temperature in reversible manner, the nematogenic mesophase reappears at the same temperature at which mesophase was persisted on heating. Thus, a present series is enantiotropically nematogenic.

The odd-even effect observed for N-I transition curve for lower homologues is attributed to shorter n-alkyl chain ' $R$ ' by sequentially added methylene unit at the left -OR group. However, the disappearance of odd-even effect from and beyond $\mathrm{C}_{10}$ homologue is attributed to the unusual status of longer n-alkyl chain R of -OR due to its coiling or bending or flexing or coupling with the major axis of the core structure which affects to the molecular rigidity and/ or flexibility and, the end to end attractions. Extrapolation of N-I transition curve to the left in a phase diagram predicts LTT for $\mathrm{C}_{4}$ and $\mathrm{C}_{5}$ nonmesomorphs as monotropic temperatures $123^{\circ} \mathrm{C}$ and $107^{\circ} \mathrm{C}$ respectively [34,35,36,37], but, they are not realizable in actual practice because of their high crystallizing tendency. The molecular rigidity due to three phenyl rings and two central bridges are constant throughout the novel series for homologues, but the changing molecular length from homologue to homologue in the same series due to changing number of methylene units in n-alkyl ' $R$ ' chain of OR group induces different magnitudes of flexibility contribution to total flexibility including flexibility of common $-\mathrm{C}_{16} \mathrm{H}_{33} \mathrm{n}$-alkyl chain ' $\mathrm{R}$ ' present at the tail end group $-\mathrm{OC}_{16} \mathrm{H}_{33}$ at the other (right) end. Thus, effective molecular flexibility occurred due to difference of polarities between two end groups plays the role for nematic mesophase formation or in general, mesophase formation. Thus changing trends in mesomorphic behaviours of a present series from homologue to homologue is attributed to the effective flexibility of each chalconyl ester nonlinear homologue molecule. The mesomorphic behaviours of present novel series are compared with the structurally analogous series as shown below in figure-3.

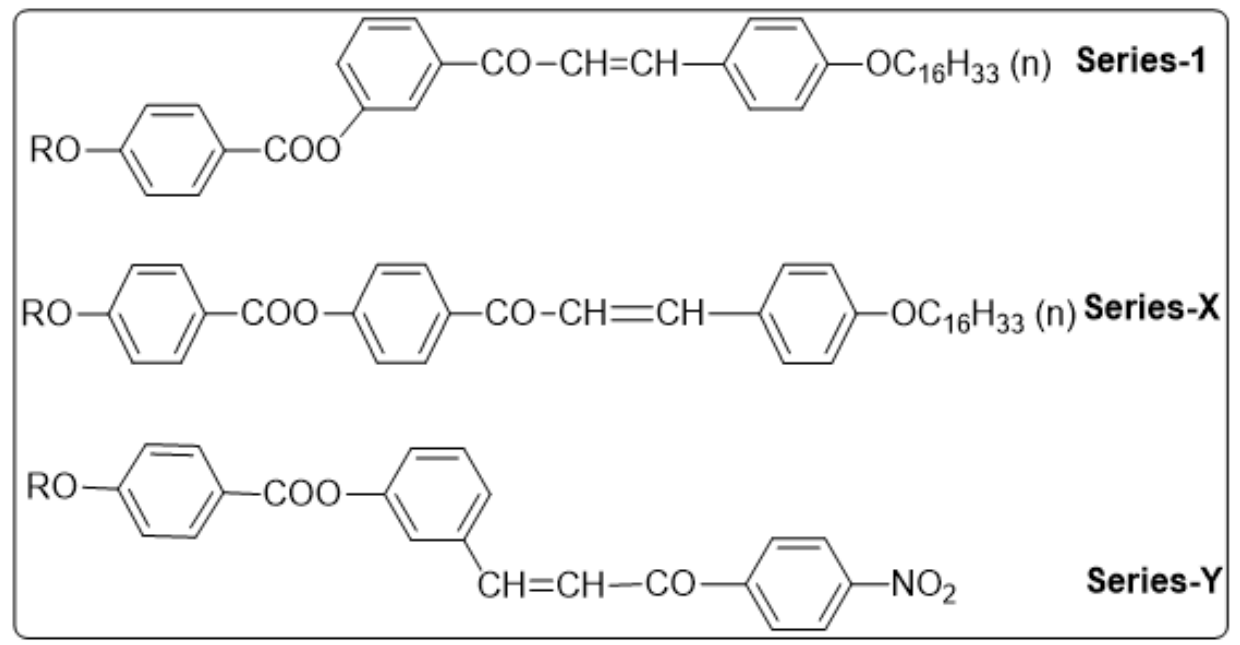

Figure 3: Structurally Similar Series

Homologous series- 1 and $\mathrm{X}$ are identical with respect to three phenyl rings, two central bridges, joining phenyl rings and two flexible terminal end groups ( $-\mathrm{OR}$ and $-\mathrm{OC}_{16} \mathrm{H}_{33}$ ). But, they differ with respect to their geometrical shapes linear and nonlinear respectively for the same homologue from series to series. Therefore they differ with respect to combined effects of molecular rigidity and flexibility, including intermolecular distance and molecular polarizability 
which operates LC behaviours of series. Homologous series-1 and Y are identical with respect to geometrical shapes, three phenyl rings, two central bridges and the left -OR group for the same homologue, but they differ with tail ended $-\mathrm{NO} 2$ and $-\mathrm{OC}_{16} \mathrm{H}_{33}$ groups. Therefore, the combined effects of molecular rigidity and flexibility for the same homologue from series to series and from homologue to homologue in the same series causes difference. Thus, variations in mesomorphic (LC) properties are attributed to the magnitudes of differing features of ( shapes and terminal end groups) each series for the same homologue and from homologue to homologue in the same series. Following table-4, represents some thermometric mesogenic properties of each series in comparative manner.

Table 4: Average thermal stability in ${ }^{\circ} \mathrm{C}$

\begin{tabular}{|c|c|c|c|}
\hline Series $\longrightarrow$ & 1 & $\mathbf{X}$ & $\mathbf{Y}$ \\
\hline $\begin{array}{c}\text { Sm-N or Sm-I } \\
\text { Commencement of } \\
\text { Smectic phase }\end{array}$ & - & - & - \\
\hline $\begin{array}{c}\text { N-I } \\
\text { Commencement of } \\
\text { Nematic phase }\end{array}$ & $\begin{array}{c}104.5 \\
\left(\mathrm{C}_{6}-\mathrm{C}_{18}\right) \\
\mathrm{C}_{6}\end{array}$ & $\begin{array}{c}113.14 \\
\left(\mathrm{C}_{6}-\mathrm{C}_{18}\right) \\
\mathrm{C}_{6}\end{array}$ & $\begin{array}{c}158.25 \\
\left(\mathrm{C}_{3}-\mathrm{C}_{16}\right) \\
\mathrm{C}_{3}\end{array}$ \\
\hline $\begin{array}{c}\text { Degree of } \\
\text { mesomorphism in } \\
{ }^{\circ} \mathrm{C} \text { from minimum } \\
\text { to maximum }\end{array}$ & $\begin{array}{l}13.0 \text { to } 37.0 \\
\mathrm{C}_{10} \quad \mathrm{C}_{6}\end{array}$ & $\begin{array}{lll}10.0 & \text { to } 26.0 \\
\mathrm{C}_{8} & & \mathrm{C}_{10}\end{array}$ & $\begin{array}{ccc}16.0 & \text { to } & 60.0 \\
\mathrm{C}_{3} & & \mathrm{C}_{6}\end{array}$ \\
\hline
\end{tabular}

Table-4 indicates that,

- The homologous series $1, \mathrm{X}$ and $\mathrm{Y}$ under comparison are nematogenic with absence of smectogenic property

- Mesomorphism commences earliest from $\mathrm{C}_{3}$ homologue of a series-Y, but it commences identically from $\mathrm{C}_{6}$ homologue for linear and nonlinear series- 1 and $\mathrm{X}$.

- Thermal stability for nematic are in increasing order from series-1 to series-X to series-Y.

- The degree of mesomorphism of series-1 is lower than a nonlinear series-Y and it is higher than a linear series-X.

- $\quad$ N-I transition curves exhibited odd-even effect for series-1 and Y except series-X.

The exhibition of nematic property and missing of smectic property by the homologous series $1, \mathrm{X}$ and $\mathrm{Y}$ are commonly understandable by the suitable magnitudes of anisotropic forces of intermolecular end to end attractions and favourable molecular polarities and polarizability induced by terminal groups which are sufficient to arrange molecules to exhibit nematic mesophase formation under floated condition but, the same intermolecular dispersion forces and dipole-dipole interactions are insufficient to maintain sliding layered molecular arrangement in floating condition, which fails the exhibition of smectogenic character in all the series under comparison. The thermal stability of series- $X$ is higher than a present novel series because, the intermolecular distance between any two molecules for series-X of linear shape are closer than a nonlinear series- 1 i.e. end to end attractions are stronger enough to facilitate higher transition temperatures and higher mathematical value of thermal stability. A homologous series being geometrically nonlinear, the intermolecular distance factors predominates against induced polarizability factor acting against each other for the same reason of intermolecular closeness. However, the degree of mesomorphism of series-1 of present investigation is a little bit more than a series-X. This difference of 
nematogenic degree of mesomorphism is attributed to the magnitudes of resistivity offered by particular homologue of favourable or unfavourable status of longer or shorter n-alkyl chain under exposed thermal vibrations. The commencement of mesomorphicphase formation takes place from $\mathrm{C}_{6}$ homologue which suggest that, the extent of molecular noncoplanarity of series- 1 and $\mathrm{X}$ are identically equivalent i.e. the extent of molecular noncoplanarity are ineffective by linearity of molecules for the same homologue of same terminal groups or for the isomeric series- 1 and X. Now on comparing nonlinear analogous series- 1 and $\mathrm{Y}$, the polarity difference of terminal groups for the same homologue between $-\mathrm{OR}$ and $-\mathrm{NO}_{2}$ raises or vary thermal stabilities, the degree of mesomorphism and the extent of molecular noncoplanarity which commences the mesophase formation worth earlier from $\mathrm{C}_{3}$ homologue (series-Y) instead of $\mathrm{C}_{6}$ homologue, which occurs in case of series-10r series-X.

\section{CONCLUSIONS}

- Homologous series of present investigation of nonlinear shape, whose transition temperatures are lower than an isomeric series of linear shape. Consequently the average value of N-I thermal stability is reduced for nonlinear series than an isomeric linear series.

- Degree of mesomorphism may fluctuate depending upon the status of n-alkyl chain ' $R$ ' of OR terminal or the group polarity situated at other end of a molecule.

- The group efficiency order derived on the basis of (a) thermal stability (b) early commencement of mesophase (c) Degree of mesomorphism for nematic are as under for the same homologue.

(a) Nematic

$-\mathrm{NO}_{2}>$ linear series $\left(-\mathrm{OC}_{16} \mathrm{H}_{33}\right)>$ nonlinear series $\left(-\mathrm{OC}_{16} \mathrm{H}_{33}\right)$

(b) Nematic

$-\mathrm{NO}_{2}>$ linear series $\left(-\mathrm{OC}_{16} \mathrm{H}_{33}\right)=$ nonlinear series $\left(-\mathrm{OC}_{16} \mathrm{H}_{33}\right)$

(c) Nematic

$-\mathrm{NO}_{2}>$ nonlinear series $\left(-\mathrm{OC}_{16} \mathrm{H}_{33}\right)>$ linear series $\left(-\mathrm{OC}_{16} \mathrm{H}_{33}\right)$

- Combined effect of molecular rigidity and flexibility of suitable magnitudes induces mesomorphism; respect of shape or size.

- A phenomena of mesomorphism is very sensitive and susceptible to molecular structure.

- LC property of thermotropic chalconyl derivatives can be brought down by twenty degree celsius by study of binary systems and their biological activity can be useful as antibacterial, antimalarial, anticancer etc in the pharmaceutical preparation.

- Present investigation supports and raises the credibility to the conclusions drawn earlier.

\section{Acknowledgement}

Authors acknowledge thanks to Dr. R. R. Shah, principal of K. K. Shah Jarodwala Maninagar Science College, Ahmedabad. Authors also thank to Dr. A. V. Doshi, Ex-principal of M.V.M. Science and Home Sci. College - Rajkot for his constant support, inspirations and help, as and when needed during the course of present investigation. Authors thank to NFDD Centre for the analytical and spectral services.

\section{References}

[1] F. Reinitzer, Monatsh 9,421, (1888).

[2] W.S.Kim, S.J. Elston, and F.P. Raynes, Display29 (2008) PP.458-463.

[3] S.Narmura. Advance LCD technologies, Displays 22 (1) (2001) PP. 
[4] G.W. Gray and P.A. Winster (Eds) Liquid Crystal and plastic crystals, chapter-6.2, The role of liquid crystal in life processes by G.T. Stewart, Vol-1,PP.308-326.

[5] C.A.Calliste, J.Cle Bail, P.Trouilas, C Poug, A.J.Chulia, L.J.Durous, Anticancer, Res. 2001, 21, 3949-3956.

[6] Y.Jahng, L.Zhao, Y.Moon, A.Basnet, E.Kim, H.W.Chang, H.K.Ju, T.C.Jeong, E.S.Lee, BioOrg, Med.Chem.Lett.2004, 14, 2559-2562.

[7] Upendra K Jain, Rich K Bhatia, Akkinepally R. Rao, Ranjit singh, Saxsena Ajit K and Seha lrun " Design and Development of Halogenated Chalcone derivatives as potential anticancer Agents “ Tropical Journal of pharmaceutical Research, January 2014: 13(1), 73-80.

[8] Prajkata P. Gaikwad , Desai Maya T. "Liquid crystalline phase and its Pharma application" International journal of Pharma Research and Review, Dec. 2013; 2 (12); 40-52.

[9] E. Hertz, B. Lavorel and O.Faucher, Optical imagine by molecular gas, Nature photon; 5 (2011) PP.783.

[10] C.T. Imrie, Liq. Crystal dimers. struct. Bond 95 (1999) PP. 149-192.

[11] Gray G.W.(1974) ln; Gray G.W. and P.A.Winsor P.A. (eds) liquid crystal and plastic crystals, Chapter-4, Volume-1, PP-103-153.

[12] Gray G.W., Molecular Structure and properties of liquid crystals, Academic press, Landon, 1962.

[13] Gray G.W. and Jones B., Mesomorphism and chemical constitution part-3, The effect of halogen substitution on the 4-Alkoxy benzoic acids, Journal of chemical society (1954) PP, 25562562.

[14] P.A.Henderson, O.Niemeyer, and C.T.Imrie, Methylene-linked liquid crystal dimers, Liq.Cryst.28 (2001), PP. 463-472.

[15] Dermus D., Plenary lectures 100 years of liquid crystals chemistry, Thermotropic liquid crystals with conventional and unconventional molecular structures, Liq. Cryst, 5 (1998). PP. 75100 .

[16] Dermus D., 100 years of liquid crystals chemistry, mol. Cryst. 165 (1998) PP.45-84.

[17] lmrie C.T and Luckhrust G.R, “ Liquid Dimers and Oligomers in handbook of Liquid Crystal, law molecular liquid crystals; Vol. 2B, Demus D., Goodby J.W., Graw G.W., Spiess H. and Vill V. eds, Willey-VCH weinhe 1998, PP-801-833.

[18] Doshi et al (i) Suthar D.M. and Doshi A.V., Mol. Cryst. Liq. Cryst. Vol. 575, PP.76-83. (ii) Chauhan H.N. and Doshi A.V., Mol.Cryst. Liq. Cryst. Vol. 570, PP. 92-100 (2013). (iii) Chaudhari R.P., Chauhan M.L. and Doshi A.V., Mol.Cryst. Liq. Cryst. Vol. 575, PP. 88-95(2013) (iv) Bhoya U.C., Vyas N.N. and Doshi A.V., Mol. Cryst. Liq. Cryst. Vol. 552. PP.104-110. (2012).

[19] Patel B.H. and Doshi A.V. "Novel Cinnamates Esters-Synthesis and Mesomorphic Properties in Relation to Molecular Structure., Mol.Cryst.Liq.Cryst., vol-605,PP.42-51 (2015).

[20] Patel B.H. and Doshi A.V. "Synthesis and Mesomorphic Properties of a Novel Ester Homologous Series: 4-(4'-n-alkoxy benzoyloxy) benzyl cinnamates" Mol. Cryst. Liq. Cryst. Vol606, PP. 56-65(2015).

[21] Doshi A.V., Joshi C.G, Patel V.R. " Synthesis and Study of Liquid Crystallinity of Benzoates Derivatives in a Laterally substituted Homologous series: n-Propyl-o-[p'-n-alkoxy benzoyloxy] benzoates. Der Pharma Chemica, 3(5): 233-239.(2011) 
[22] Doshi A.V., Patel R.B.,"Study of a new homologous series of Cis Cinnamate ester of Mesogens: n-Hexyl-p-(p'-n-alkoxy cinnamoyloxy) cinnamates. Der Pharma Chemica, 3(1): 338348.(2011)

[23] Doshi A.V., Patel V.R., "Study of Azo ester mesogens: 4-(4'-n-alkoxy benzoyloxy)-3Methoxy-phenyl azo-4''-Nitrobenzene. Der Pharma Chemica, 2(6): 439-436.(2010)

[24] Doshi A.V., Makwana N.G., "Synthesis and Study of a new mesogenic Homologous series:4(4'-n-alkoxy benzoyloxy)-3,5-dichloro phenylazo-4' '-methyl benzene., Der Pharma Chemica, 3(2): 433-439.(2011)

[25] Chauhan B.C., Doshi A.V.,"Synthesis and study of Thermotropic Mesogenic homologous series: p-(p'-n-alkoxy benzoyloxy)-m-chlorophenyl azo-p'"- chlorobenzene. Der Pharma Chemica, 3(1): 172-180. (2011)

[26] Bhoya U.C., Doshi A.V., Patel R.B., "Study of new homologous series of azoester mesogens: p-(p'-n-alkoxy benzoyloxy)-m-methylphenylazo-p' '-methoxybenzene. Der Pharma Chemica, 3(3): 115-123.(2011)

[27] Hird. M, Toyne. K.J, Gray G.W., Day S.E. and Mc. Donell D.G. (1993), Liq. Cryst.15 PP. 123. [28] P.J. Collings and M. Hird (1997), Introduction of Liquid crystals chemistry and Physics, Taylor and Francis Ltd. U.K.1998.

[29] Macros . M, Omenat. A, Serrano. J.L and Ezcurra. A(1992), Adv. Matter, 4, 285.

[30] Hird. M, Toyne. K.J,Gray G.W., Day S.E. (1993) Liq. Cryst.14, PP. 741.

[31] Dave J.S and Vora R.A (1970). In: J.F. Johnson and R.S. Porter, (eds), (Liquid Crystals and ordered fluids, Plenum Press: New York, P.447.

[32] Vogel.A.I. "Textbook of practical organic chemistry", $5^{\text {th }}$ ed. ELBS and Longmann, London.(1989) 946.

[33] Uhood J.A., international Journal of Molecular Science., vol.12; PP. 3182-3190 (2011).

[34] ohar J.M and Doshi A.V., "Studies on mixed mesomorphism: Determination of latent transition temperature (LTT) by extrapolation" proceeding of Indian Acad. Of Science-Bangalore, Vol-105, N0-3, June 1993, PP. 209-214.

[35] Ganatara K.J. and Doshi A.V., "Study of binary systems inducing mesophase and determination of latent Transition Temperature". Journal of Indian Chem. Soc., Vol.77, July 2000, PP. 322-325.

[36] Bhoya U.C., Vyas N.N. and Doshi A.V., Mol. Cryst. Liq. Cryst., Vol. 552. PP. 104-110. (2012).

[37] Doshi A.V., Bhoya U.C., Travadi J.J., Mol.Cryst.Liq.Cryst., Vol. 552. PP. 10-15, (2012)

[38] Vinay S. Sharma, Ravindra B. Solanki and R.B. Patel, Manuscript of the research paper entitled, "Molecular Structure and Mesomorphism: Effect of Tail/Lateral Group" submitted for publication in Mol. Cryst. Liq. Cryst. Journal with its reference no. LCMH No. 326 date $28^{\text {th }}$ April 2015.

[39] Doshi A.V., Chaudhari R.P., Mol.Cryst.Liq.Cryst., vol.570, PP. 109-116, (2013) 